\title{
Pulmonary vein signal in mitral regurgitation
}

\author{
Tim Balthazar *iD, Bart Jacobs and Jens-Uwe Voigt \\ See related research by Vignon et al., https://ccforum.biomedcentral.com/articles/10.1186/s13054-016-1400-8
}

We read the article Critical care ultrasonography in acute respiratory failure [1] by Vignon et al. with great interest. We agree that echocardiography plays an important role in the evaluation of patients with acute respiratory failure. We do not, however, agree with the statement that massive mitral regurgitation causes a reversal in pulmonary vein diastolic inflow or "D wave" as implied in Figure 2 where a case of cardiac weaning failure is presented. Since mitral regurgitation is a systolic phenomenon it can only cause reversal of the systolic "S wave" [2]. This is actually shown in the right lower panel of the figure, where the arrow points at a reversed "S wave". The "S" and "D" labels should be exchanged and the figure legend should be corrected accordingly.

\section{Authors' response}

\section{Philippe Vignon, Xavier Repessé, Antoine Vieillard-Baron and Eric Maury}

We thank Dr. Balthazar and coworkers for pointing out the erroneous figure legend and annotation in our recently published manuscript describing the clinical value of critical care ultrasonography in both the diagnostic work-up and management of patients admitted to the intensive care unit with acute respiratory failure [1]. Massive mitral regurgitation results in an extended reversal flow which reaches the left atrial posterior wall and regurgitates within pulmonary veins during systole. Accordingly, as adequately emphasized by the authors, the systolic component of the pulmonary vein Doppler pattern ( $\mathrm{S}$ wave) is either blurred or even inverted, whereas the diastolic component ( $\mathrm{D}$ wave) is markedly prominent due to associated elevated left ventricular filling pressure. During systole, $\mathrm{S}$ wave blurring or reversal has the same diagnostic value as the presence of a markedly elevated " $v$ " wave on the pulmonary capillary wedge pressure curve during right heart catheterization [3]. In this clinical setting, the predominant pulmonary vein Doppler D wave is usually associated with a predominant mitral Doppler E wave typically consistent with a normalized or even restrictive mitral Doppler pattern. These Doppler profiles reflect both the volume overload and associated increased filling pressures secondary to the massive mitral regurgitation. Of note, Doppler S wave blurring or reversal may be observed predominantly in left or right pulmonary veins when the mitral regurgitant jet is eccentric and has either a clockwise or anticlockwise propagation along left atrial walls, respectively [4].

\section{Authors' contributions \\ TB wrote manuscript. BJ and JV helped change the text of the original manuscript. All authors read and approved the final manuscript.}

\section{Competing interests}

The authors declare that they have no competing interests.

\section{Publisher's Note}

Springer Nature remains neutral with regard to jurisdictional claims in published maps and institutional affiliations.

Received: 5 March 2018 Accepted: 6 April 2018

Published online: 11 May 2018

\footnotetext{
References

1. Vignon P, Repressé X, Vieillard-Barron A, Maury E. Critical care ultrasonography in acute respiratory failure. Crit Care. 2016;20:228.

2. Teien DE, Jones M, Shiota TY, Yamada I, Sahn DJ. Doppler evaluation of severity of mitral regurgitation: relation to pulmonary venous blood flow patterns in an animal study. JACC. 1995;25(1):264-8.

3. Wisse B, Sniderman AD. Severe mitral regurgitation. N Engl J Med. 2000;343:1386

4. Attias D, Mansencal N, Auvert B, Vieillard-Baron A, Delos A, Lacombe P, N'Guetta R, Jardin F, Dubourg O. Prevalence, characteristics, and outcome of patients presenting with cardiogenic unilateral pulmonary edema. Circulation. 2010;122:1109-15.
}

* Correspondence: tim.balthazar@uzleuven.be

Department of cardiology, University Hospitals Leuven, Herestraat 49, 3000 Leuven, Belgium

(c) The Author(s). 2018 Open Access This article is distributed under the terms of the Creative Commons Attribution 4.0 International License (http://creativecommons.org/licenses/by/4.0/), which permits unrestricted use, distribution, and reproduction in any medium, provided you give appropriate credit to the original author(s) and the source, provide a link to the Creative Commons license, and indicate if changes were made. The Creative Commons Public Domain Dedication waiver (http://creativecommons.org/publicdomain/zero/1.0/) applies to the data made available in this article, unless otherwise stated. 